\title{
Lead Placement
}

National Cancer Institute

\section{Source}

National Cancer Institute. Lead Placement. NCI Thesaurus. Code C71100.

The spatial property of the way in which an electrocardiogram lead is placed on the body. 